This is an author produced version of a paper published in Preventive Veterinary Medicine. This paper has been peer-reviewed. It does not include the journal pagination.

Citation for the published paper:

Petersson, K-J., Strandberg, E., Gustafsson, H., Royal, M.D. and Berglund, B. (2008) Detection of delayed cyclicity in dairy cows based on progesterone content in monthly milk samples. Preventive Veterinary

Medicine.Volume 86: issue 1-2, pages 153-163. http://dx.doi.org/10.1016/j.prevetmed.2008.04.001

Access to the published version may require journal subscription. Published with permission from Elsevier.

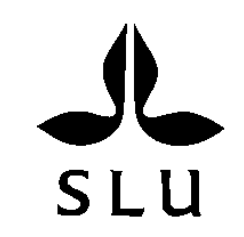

Epsilon Open Archive http://epsilon.slu.se 


\title{
Detection of delayed cyclicity in dairy cows based on progesterone content in monthly milk samples
}

\author{
K.-J. Petersson ${ }^{a, *}$, E. Strandberg ${ }^{a}$, H. Gustafsson ${ }^{b, c}$, M.D. Royal ${ }^{d}$, and \\ B. Berglund ${ }^{a}$
}

${ }^{a}$ Department of Animal Breeding and Genetics, Swedish University of Agricultural Sciences, Centre for Reproductive Biology in Uppsala, PO Box 7023, SE-750 07 Uppsala, Sweden

${ }^{b}$ Swedish Dairy Association, PO Box 7039, SE-750 07 Uppsala, Sweden

${ }^{\mathrm{c}}$ Department of Clinical Sciences, Division of Reproduction, Swedish University of Agricultural Sciences, PO Box 7054, SE-750 07 Uppsala, Sweden

${ }^{\mathrm{d}}$ Department of Veterinary Clinical Science, Faculty of Veterinary Science, University of Liverpool, Leahurst, Neston, South Wirral CH64 7TE, UK

*Corresponding author,

Tel: +46-18-671971; Fax: +46-18-672848; E-mail address: karl-johan.petersson@hgen.slu.se

\begin{abstract}
We examined whether infrequent milk sampling for progesterone analysis could be used as a management or diagnostic tool by the dairy farmer to predict delayed ovarian cyclicity in dairy cows. The data included 1040 lactations from 324 Swedish Red cows and 183 Swedish Holstein cows and were randomly divided into two datasets. A logistic regression model was fit to the first dataset and the model was then validated on the other dataset. The model was also validated using a British dataset comprising 1212 lactations from 1080 British Holstein-Friesian cows. The dependent variable was whether delayed ovarian cyclicity occurred or not, delayed ovarian cyclicity defined as progesterone levels below threshold value for the first 56 or 45 days postpartum in the Swedish or British dataset, respectively. The basic model included the effects of breed, parity, season and housing type. To the basic model various progesterone-based measurements were added. These were the interval from calving to commencement of luteal activity and the percentage of samples with luteal activity within 60 days after calving, using all samples in the databases or one sample per month. The accuracy of the conditional probability of delayed ovarian cyclicity calculated with the different models was obtained using receiver operating characteristic (ROC) curves and calculating the area under curve. Sensitivity and specificity were calculated for cut-off probabilities using the ROC analyses. The accuracy was highest (0.940.99 ) when including the progesterone measurements based on milk sampling for progesterone analysis $2-3$ times per week. The accuracy was between 0.85 and 0.88 when the progesterone measurements with monthly milk sampling were added to the model and 0.76 or 0.67 with the basic model. This study clearly shows that infrequent milk sampling for progesterone analysis, such as once a month as in the regular milk recording system, could be used to predict delayed ovarian cyclicity in dairy cows. This increases the opportunity for earlier treatment of anovulatory dairy cows and may therefore decrease involuntarily extended calving intervals in the herd.
\end{abstract}

Keywords: Progesterone; Fertility; Management; Diagnostic test 


\section{Introduction}

In Swedish dairy cows, delayed ovarian cyclicity was found to be the most frequent ovarian dysfunction, occurring in $16 \%$ of lactations (Petersson et al., 2006a). Cows with this ovarian dysfunction had, on average, 17 days longer intervals from calving to first service and 22 days longer intervals from calving to conception compared with normal cows (Petersson et al., 2006a). An increased incidence of delayed ovarian cyclicity is one important cause of the gradual increase of eight days in the interval from calving to first service that has been observed in Sweden during the last ten years (Swedish Dairy Association, 2006). However, Royal et al. (2000) observed no change in the incidence of delayed cyclicity profiles but calving intervals were 20 days longer when comparing a dataset from 1995 to 1998 with an earlier dataset from 1975 to 1982 for British Holstein-Friesian cows.

To obtain a calving interval of 1 year, the cow must be pregnant by approximately 85 days postpartum. Increased interval to conception increases the calving interval, which has economic consequences for the dairy farmer. Strandberg and Oltenacu (1989) found that each day of increase in the interval from calving to pregnancy lowered the net return per year per cow from $0.3 \mathrm{SEK}$ (\$0.05) to 11.6 SEK (\$1.80). In a British study, Esslemont et al. (2001) showed that each extra day in the time to conception had a net cost of $£ 1.73$ (\$2.49) to $£ 6.52$ (\$9.39) depending on yield level, quota costs and when in the postpartum period the delay occurred.

Delayed onset of ovarian cyclicity includes mainly two anovulatory clinical conditions: anoestrus defined as growth of follicles up to ovulatory size but no ovulation, and ovarian cysts. Both conditions have complicated endocrinological backgrounds, reviewed by Wiltbank et al. (2002). Cows not observed in oestrus by the herdsman are generally subjected to a clinical examination and treatment by a veterinarian, but often too late to get an economically optimal calving interval. Moreover, the traditional genital clinical examination, performed by rectal palpation, is often inaccurate. McLeod and Williams (1991) found that 70\% of diagnosed follicular cysts, $58 \%$ of diagnosed anoestrus, and $30 \%$ of diagnosed normal cases were incorrectly diagnosed by rectal examination alone, compared with diagnoses based on progesterone analysis of milk samples. The same authors concluded that rectal palpation was an unsatisfactory method to monitor ovarian function, which may result in misdiagnosis and administration of inappropriate and unnecessary treatments. Moreover the use of ultrasonography for routine examination of the reproductive tract of dairy cows is growing (Fricke, 2002). However, the technique gives limited information regarding the physiological or endocrine status of the ovarian structures.

In a previous study we have shown that progesterone analysis of milk samples in the regular milk recording could be used with high accuracy in genetic evaluation of the interval from calving to commencement of luteal activity (Petersson et al., 2007). This suggests that a systematic involvement of progesterone-based traits in a breeding programme should gradually lead to more cows that ovulate early after calving in dairy herds. However, this fact does not diminish the importance of an early and accurate detection of cows ovulating late after calving.

In Sweden and the UK, milk samples from approximately $85 \%$ of all dairy cows are sent to central laboratories for analysis of several milk constituents. All of these cows are also identified in the milk recording system with information such as breed, parity and milk yield. Continuous information of the probability of normal ovarian cyclicity during the postpartum period based on progesterone 
profiles would help both the herdsman and the veterinarian to identify abnormal cows and to take the correct actions and therefore increase the probability of reaching reproductive goals.

The aim of this study was to investigate whether milk progesterone measurements based on monthly milk samples could be used as a diagnostic tool for delayed cyclicity in dairy cows. Such a tool would increase the opportunity for earlier treatment of the individual cow or changed herd management and therefore decrease involuntarily extended calving intervals.

\section{Material and methods}

\subsection{Animals}

Data were collected between December 1987 and December 2002 in the experimental herd of the Department of Animal Breeding and Genetics, Swedish University of Agricultural Sciences (Uppsala, Sweden). For further details, see Petersson et al. (2006a, b). A total of 1040 lactations were included from 507 dairy cows of Swedish Red (SR, $\mathrm{n}=324$ cows) and Swedish Holstein $(\mathrm{SH}, \mathrm{n}=183$ cows) breeds. Cows were in their $1^{\text {st }}$ to $10^{\text {th }}$ lactations, but were grouped as $1^{\text {st }}, 2^{\text {nd }}$, and $\geq 3^{\text {rd }}$ lactation. Two housing systems were used at the experimental farm: tiestalls or a loose-housing system. Records of housing were available from 1992 to 2001; before 1992, the experimental herd was kept at another location where all the animals were tied. From 1994 onward, cows were subjected to a calving interval trial, in which they were inseminated for planned calving intervals of either 12 or 15 months. That trial is thoroughly described by Ratnayake et al. (1998). Moreover, the SR cows were in a selection trial for high or low fat content in milk; see Janson and Ahlin (1992) for more information.

Detection of oestrus was conducted visually thrice daily at fixed times. The strength of oestrus symptoms was scored according to the following scale: $0=$ no oestrus, 1 = uncertain, 2 = weak, 3 =normal, $4=$ strong, and from 1995 onwards: 5 = very strong, based on occurrence of different signs such as bellowing, mounting behaviour, vulvar swelling, licking, and vulvar discharge. Cows with planned calving intervals of 12 and 15 months were not inseminated before 50 days and 140 days postpartum, respectively. A maximum of 5 artificial inseminations (AIs) were allowed per breeding period, with breeding periods restricted to a maximum of 130 days between first and last AI. Thereafter, cows were culled because of infertility. All AI were performed by experienced AI technicians. Three different reproductive disorders were included in our study: anoestrus, ovarian cysts and endometritis. The reproductive health of all cows was examined by a veterinarian in week 3 and 6 postpartum. Treatments of reproductive disorders, i.e. anoestrus, ovarian cysts and endometritis, have been described previously (Petersson et al., 2006a). All cows treated before commencement of luteal activity was excluded from the study.

\subsection{Cyclicity measures}

Milk sampling for progesterone analysis started during the second week after parturition. Milk was sampled twice weekly until ovarian cyclical activity was detected, defined as the first sample indicating luteal activity and verified by the next sample. Thereafter sampling was performed once a week until first insemination. Progesterone thresholds for luteal activity to determine change in sampling frequency were initially based on information from the producers of the different radioimmunoassay kits. 
Progesterone was analyzed in whole milk. The sample (about $5 \mathrm{ml}$ of milk) was taken within 60 min after milking, collected into tubes containing $100 \mu \mathrm{L}$ of preservative (Bronopol $2 \%+$ methylene blue $0.05 \%$ ) and stored at $4{ }^{\circ} \mathrm{C}$ until radioimmunoassay. Three different radioimmunoassay kits were used during the study. From the start of data collection until 1995, the Farmose kit was used (Orion Diagnostica, Espoo, Finland). The company then introduced a new assay, Spectra, which was used until 1998. From 1998, a Coat-A-Count kit was used (Diagnostic Products Corporation, Los Angeles, CA, USA). The intra-assay coefficients of variation were below 0.10 for all three kits and the corresponding inter-assay coefficients of variation was below 0.16 (Ratnayake et al., 1998). Progesterone observations from estimated day of ovulation were used to set thresholds for luteal activity for each of the three kits using a subset of data with 275, 284 and 464 progesterone observations for the Farmose, Spectra, and Coat-A-Count kits, respectively. Day of ovulation was estimated as the day after detection of oestrus (normal to very strong oestrous signs) or the day before onset of metoestrous bleeding. The threshold for luteal activity was set using the progesterone concentration that $95 \%$ of the estimated days of ovulation fell below. The thresholds used were 8.0, 3.0 and $1.3 \mathrm{nmol} / \mathrm{l}$ for the Farmose, Spectra, and Coat-ACount kits, respectively.

Progesterone concentrations were plotted against days postpartum to create individual progesterone profiles until first AI was performed. Delayed cyclicity was defined as progesterone profile with progesterone levels below threshold for the first 56 days postpartum. Profiles were excluded if the sampling scheme was not followed; that is, if the interval between two consecutive samples was $\geq 10$ days before first AI. Ninety-two profiles were consequently excluded.

All milk samples for progesterone analysis taken within the first 60 days postpartum for a cow were used to calculate the percentage of samples above the threshold, and hence, percentage luteal activity (PLA). This measure was included because it is easy to automate and it yields information on what happens after cyclicity has started (Petersson et al., 2006a). For PLA based on random monthly sampling $\left(\mathrm{PLA}_{\mathrm{m}}\right)$, a sample randomly chosen from the first 4 weeks of lactation together with a sample taken 30-37 days later were used. The random selection was done utilizing SAS procedure SUREYSELECT (SAS Institute Inc., 2002). The possible values for PLA $_{m}$ were $0 \%, 50 \%$ and $100 \%$. The first postpartum progesterone value above the threshold value, using all samples for progesterone analysis for a cow, was used to define the interval from calving to commencement of luteal activity (CLA). If this period was $>60$ days it was set to 60 days. For the calculation of the interval from calving to commencement of luteal activity based on monthly random sampling $\left(\mathrm{CLA}_{\mathrm{m}}\right)$ the same sampled days as the calculation of PLA $_{m}$ was used. If the first sampled day had a progesterone level above threshold this day became $\mathrm{CLA}_{\mathrm{m}}$, whereas if the first sampled day had progesterone level below threshold and the consecutive day 30 to 37 days later had a progesterone level above threshold, this day became CLA $\mathrm{m}_{\mathrm{m}}$. If both days had low progesterone levels CLA $\mathrm{A}_{\mathrm{m}}$ was set to 60 days. The random selection of sampling day that were used for PLA $\mathrm{A}_{\mathrm{m}}$ and $\mathrm{CLA}_{\mathrm{m}}$ was done to resemble the regular milk recording. These four different progesterone measurements, PLA, PLA $\mathrm{m}_{\mathrm{m}}$ CLA and CLA $\mathrm{A}_{\mathrm{m}}$ were the hypothesized predictors for delayed cyclicity.

\subsection{Model fitting and validation on the primary dataset}

The full dataset, including 1040 lactations, was divided randomly with the SAS procedure SURVEYSELECT (SAS Institute Inc., 2002) into one test set ( $\mathrm{n}=550$ lactations) and one validation set $(n=490$ lactations). The random division was based on individual cow to avoid the same cow being present in both datasets and 
therefore exactly equal sizes were not achievable. Procedure LOGISTIC in SAS was used to fit a logistic regression model to the test data, with delayed cyclicity or not as the dependent variable. Effects that were shown to have significant associations with type of profile in a previous study were anoestrus, breed, calving interval trial, calving season, calving year group, endometritis, housing, lameness, ovarian cysts, parity, previous dry period length, type of profile in previous lactation, weight loss (Petersson et al., 2006a). Of these we selected those available in the regular milk recording and forced them in as independent variables in the basic model. The basic model included effects of breed (SR or SH), parity (1, 2, and $\geq 3$ ), season (winter: November - April and summer: May - October) and housing (tied, loose, previous location, or no information). Four models with different progesterone measurement were then fit, all had the basic descriptors forced in and each included a fixed regression on the progesterone based measurements: CLA, PLA, CLA $\mathrm{m}_{\mathrm{m}}$ or PLA $\mathrm{m}$. The final parameters of the fitted models from the logistic regression on the test dataset were then used to compute the conditional probabilities for delayed cyclicity, given the values of the explanatory variables in each observation for the validation dataset.

To examine the ability of the various progesterone measurements to discriminate between delayed cyclicity or not we used non-parametric receiver operating characteristic (ROC) curves. The non-parametric ROC curves were constructed in procedure LOGISTIC in the SAS package (SAS Institute Inc., 2002), and the area under curve (AUC) was calculated using the \%roc macro (SAS Institute Inc., 2006).

\subsection{Model validation on a secondary dataset}

To further validate the model obtained from the test dataset in the Swedish data, we accessed a dataset from the United Kingdom (Royal et al., 2000, 2002a, b; Petersson et al., 2007). This dataset was treated in the same way as the Swedish validation dataset. Thus were the final parameters of the fitted models from the logistic regression on the Swedish test dataset used to compute the conditional probabilities for delayed cyclicity, given the values of the explanatory variables in each observation for this British validation dataset. The ability of the various progesterone measurements to discriminate between delayed cyclicity or not was examined using ROC curves as described in the previous section.

The British material was collected between October 1996 and March 1999 and comprised 1212 lactations from 1080 British Holstein-Friesian cows in eight commercial herds. These cows were in their 1st to 9th lactations, but were grouped as 1 st, $2 \mathrm{nd}$, and $\geq 3$ rd lactation. Milk samples for progesterone analysis were taken three times per week (Monday, Wednesday and Friday) from 2 to 8 days postpartum until a maximum of 24 days after the first service (for further details see Royal et al., 2000). Progesterone concentration was measured in unextracted samples of whole milk using ELISA (Ridgeway Science Ltd, Alvington, Gloucestershire, UK). The intra-assay coefficients of variation, calculated using a representative sample of 100 assays, for control standards at $6.4 \mathrm{nmol} / \mathrm{l}$ and 25.4 $\mathrm{nmol} / \mathrm{l}$ were 0.129 and 0.060 , respectively. The inter-assay coefficients of variation were 0.127 and 0.081 for $6.4 \mathrm{nmol} / 1$ and $25.4 \mathrm{nmol} / 1$, respectively.

Most of the progesterone measurements were calculated as for the Swedish data, except for delayed cyclicity. In the British material delayed cyclicity was defined as milk progesterone $<9.5 \mathrm{nmol} / 1$ for $\geq 45$ days after calving. The random sampling for PLAm and CLAm differed slightly in number of days between the two random samples, which were 28 days in the British data and 30-37 days in the Swedish data. This minor difference is a result of the strict sampling regime in the 
British data, making it possible to take two samples exactly 4 weeks apart. Other differences between the two studied materials were that all cows in the British material were Holstein-Friesians and all these cows were kept in loose-housing systems. The differences between the two datasets (one from Sweden and one from the UK) are results of different set ups when starting data collection. However, we have found that the differences between the datasets are not too large to include them in the same study as we have done here.

\section{Results}

The overall incidence of lactations with delayed cyclicity was $15.9 \%(n=165)$ of the 1040 lactations in the Swedish material. In the test dataset 13.8\% $(n=76)$ had delayed cyclicity; in the Swedish validation dataset, $18.2 \%(\mathrm{n}=89)$ had delayed cyclicity. In the UK dataset the incidence of delayed cyclicity was $15.2 \%(\mathrm{n}=$ 184).

Table 1 shows the estimated log-odds of delayed ovarian cyclicity obtained from the test dataset. These were applied to calculate the probabilities for delayed cyclicity in the two validation datasets. The estimated log-odds of delayed ovarian cyclicity decreased by 2.73 for each $50 \%$ increase in $\mathrm{PLA}_{\mathrm{m}}$ and 0.35 for each percent increase in PLA. For 1 day longer CLA $\mathrm{m}_{\mathrm{m}}$ or CLA the estimated log-odds of delayed ovarian cyclicity increased by 0.12 or 0.16 , respectively.

In Fig. 1, the ROC plots are shown for the five different models applied on the Swedish validation dataset. The two measurements CLA and PLA based on all samples had the highest AUC followed by CLA $A_{m}$ and PLA $A_{m}$ which were based on monthly random sampling. This was true for both validation datasets (Table 2). $\mathrm{PLA}_{\mathrm{m}}$ had significantly higher AUC than the basic model. The AUC confidence interval for PLA excluded that of PLA $A_{m}$ and the AUC confidence interval for CLA excluded that of $\mathrm{CLA}_{\mathrm{m}}$ in both validation datasets.

Fig. 2 is a plot of sensitivity and specificity against various cut-off probabilities for $\mathrm{PLA}_{\mathrm{m}}$ for the Swedish validation dataset. The cut-off point where the sensitivity and specificity lines cross each other for each model in both validation datasets was used to calculate the sensitivity, specificity and percentage of correct diagnosed lactations with or without delayed cyclicity for each model in both validation datasets (Table 3 ). The cut-offs were selected by visual observation of the graph for each model in both datasets. The estimated sensitivity and specificity values at the plotted cross-over point were not always equal to one another because the curves were not smoothed. 
Table 1. Parameter estimates and standard error of a basic logistic model and four models with different progesterone parameter fixed effects for delayed ovarian cyclicity in a test dataset ( $\mathrm{n}=550$ lactaions) from a Swedish research herd, 1987-2002

\begin{tabular}{|c|c|c|c|c|c|c|c|c|c|c|}
\hline Fixed effect & Basic & S.E. & $\mathrm{PLA}_{\mathrm{m}}{ }^{\mathrm{a}}$ & S.E. & $\mathrm{CLA}_{\mathrm{m}}$ & S.E. & PLA & S.E. & CLA & S.E. \\
\hline Intercept & $-2.04 * *$ & 0.17 & $-0.91 * *$ & 0.19 & $-8.58 * *$ & 1.30 & $2.89 * *$ & 0.54 & $-8.60 * *$ & 0.86 \\
\hline \multicolumn{11}{|l|}{ Breed } \\
\hline \multicolumn{11}{|l|}{ Housing } \\
\hline No housing info vs. tied & -0.27 & 0.31 & -0.42 & 0.34 & -0.37 & 0.33 & -0.12 & 0.54 & 0.10 & 0.41 \\
\hline Previous location vs. tied & 0.38 & 0.24 & $0.59 *$ & 0.28 & 0.44 & 0.26 & 0.35 & 0.54 & 0.15 & 0.34 \\
\hline Parity 1 vs. 3 & $0.71 * *$ & 0.18 & $0.63 * *$ & 0.20 & $0.62 * *$ & 0.19 & 0.02 & 0.38 & 0.31 & 0.24 \\
\hline Parity 2 vs. 3 & $-0.47 *$ & 0.22 & $-0.52 *$ & 0.24 & -0.46 & 0.23 & -0.27 & 0.46 & -0.29 & 0.29 \\
\hline \multicolumn{11}{|l|}{ Season } \\
\hline Winter vs. summer & $0.60 * *$ & 0.14 & $0.44 * *$ & 0.15 & $0.46^{* *}$ & 0.15 & 0.10 & 0.30 & 0.18 & 0.19 \\
\hline Regression on PLA $_{\mathrm{m}}, \mathrm{CLA}_{\mathrm{m}}$, PLA or CLA & & & $-2.73^{* *}$ & 0.39 & $0.12 * *$ & 0.02 & $-0.35 * *$ & 0.05 & $0.16^{* *}$ & 0.02 \\
\hline
\end{tabular}

${ }^{\mathrm{a}} \mathrm{PLA}_{\mathrm{m}}=$ Percentage of samples with luteal activity the first 60 days postpartum, based on monthly sampling. CLA $\mathrm{m}=$ Interval from calving to commencement of luteal activity, based on monthly sampling. PLA = Percentage of samples with luteal activity the first 60 days postpartum, based on all samples. CLA $=$ Interval from calving to commencement of luteal activity, based on all samples.

$* P<0.05, * * P<0.01$. 


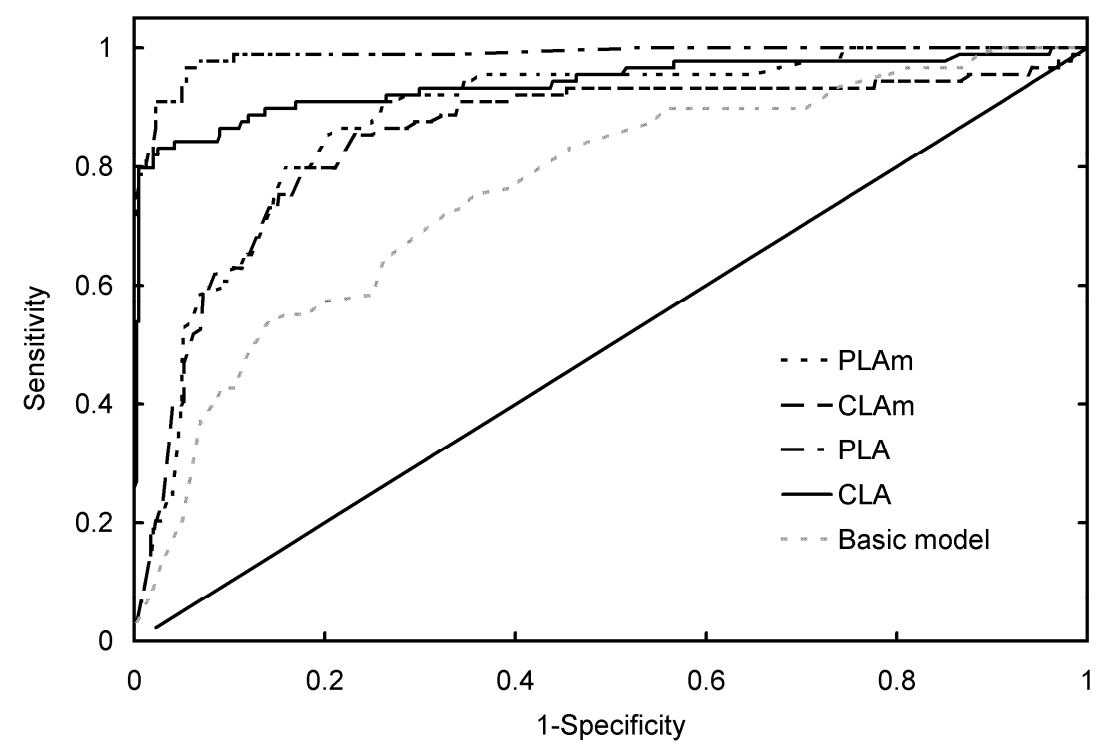

Fig. 1. Receiver operating characteristic curves for the basic model and the models including the percentage of samples with luteal activity the first 60 days postpartum, based on monthly sampling $\left(\mathrm{PLA}_{\mathrm{m}}\right)$, the interval from calving to commencement of luteal activity, based on monthly sampling $\left(\mathrm{CLA}_{\mathrm{m}}\right)$, the percentage of samples with luteal activity the first 60 days postpartum, based on all samples (PLA), and the interval from calving to commencement of luteal activity, based on all samples (CLA) for the Swedish validation dataset ( $\mathrm{n}=490$ lactations). The grey solid line is the 0.5 line, which is the limit for the predictive ability of a model.

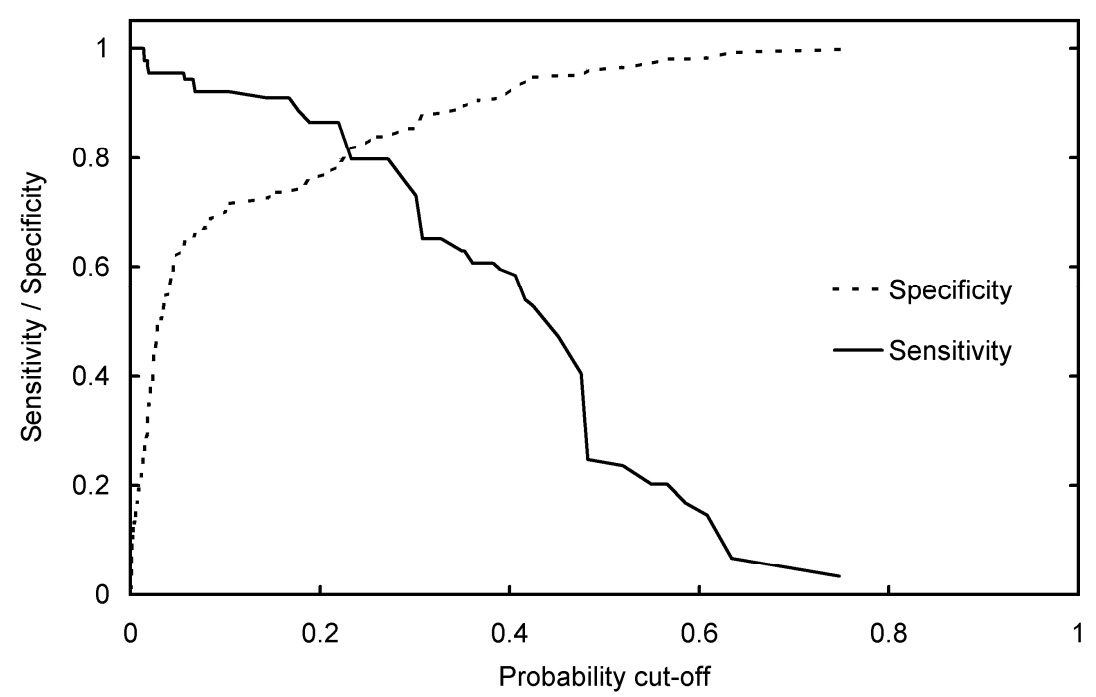

Fig. 2. Example of a plot of sensitivity and specificity against probability cut-off values. The figure illustrates the plot for percentage of samples with luteal activity within 60 days after calving with monthly random sampling in the Swedish validation dataset $(n=490$ lactations). 
Table 2. Summary of the non-parametric receiver operating characteristic (ROC) analysis with the area under curve (AUC) for a Swedish validation dataset from a Swedish research farm, 1987-2002, and a British validation dataset from 8 commercial farms, 1996-1999

\begin{tabular}{|c|c|c|c|}
\hline Model & AUC & S.E. & $95 \% \mathrm{CI}$ \\
\hline \multicolumn{4}{|c|}{ Swedish validation data $(\mathrm{n}=490)$} \\
\hline Basic model $^{\mathrm{a}}$ & 0.76 & 0.03 & $0.70,0.82$ \\
\hline $\mathrm{CLA}_{\mathrm{m}}^{\mathrm{b}}$ & 0.85 & 0.03 & $0.80,0.90$ \\
\hline $\mathrm{PLA}_{\mathrm{m}}$ & 0.88 & 0.02 & $0.84,0.92$ \\
\hline CLA & 0.94 & 0.02 & $0.90,0.98$ \\
\hline PLA & 0.99 & $<0.01$ & $0.98,1.00$ \\
\hline \multicolumn{4}{|c|}{ British validation data $(n=1212)$} \\
\hline Basic model $^{\mathrm{a}}$ & 0.66 & 0.02 & $0.62,0.71$ \\
\hline $\mathrm{CLA}_{\mathrm{m}}$ & 0.85 & 0.02 & $0.81,0.88$ \\
\hline $\mathrm{PLA}_{\mathrm{m}}$ & 0.85 & 0.02 & $0.82,0.88$ \\
\hline CLA & 0.99 & $<0.01$ & $0.98,1.00$ \\
\hline PLA & 0.98 & $<0.01$ & $0.97,0.98$ \\
\hline
\end{tabular}

${ }^{a}$ Basic model included fixed effects of breed, parity, season and housing.

${ }^{\mathrm{b}} \mathrm{CLA}_{\mathrm{m}}=$ Interval from calving to commencement of luteal activity, based on monthly sampling. PLA $_{\mathrm{m}}=$ Percentage of samples with luteal activity the first 60 days postpartum, based on monthly sampling. CLA = Interval from calving to commencement of luteal activity, based on all samples. PLA $=$ Percentage of samples with luteal activity the first 60 days postpartum, based on all samples.

Table 3. Result of classification of lactations with delayed cyclicity or not for probability cut-offs where sensitivity and specificity cross each other in plots of sensitivity and specificity against cut-off values for a Swedish validation dataset from a Swedish research farm, 1987-2002, and a British validation dataset from 8 commercial farms, 1996-1999

\begin{tabular}{|c|c|c|c|c|}
\hline & Cut-off & Sensitivity (\%) & Specificity (\%) & Correct $(\%)$ \\
\hline \multicolumn{5}{|c|}{ Swedish validation data $(\mathrm{n}=490)$} \\
\hline Basic model & 0.15 & 72 & 68 & 68 \\
\hline $\mathrm{CLA}_{\mathrm{m}}{ }^{\mathrm{a}}$ & 0.22 & 80 & 81 & 81 \\
\hline $\mathrm{PLA}_{\mathrm{m}}$ & 0.23 & 80 & 82 & 82 \\
\hline CLA & 0.16 & 89 & 88 & 88 \\
\hline PLA & 0.14 & 94 & 95 & 95 \\
\hline \multicolumn{5}{|c|}{ British validation data $(n=1212)$} \\
\hline Basic model & 0.12 & 63 & 66 & 65 \\
\hline CLA $_{\mathrm{m}}$ & 0.16 & 75 & 81 & 80 \\
\hline $\mathrm{PLA}_{\mathrm{m}}$ & 0.15 & 73 & 82 & 81 \\
\hline CLA & 0.17 & 98 & 98 & 98 \\
\hline PLA & $<0.01$ & 86 & 95 & 93 \\
\hline
\end{tabular}

${ }^{\mathrm{a}} \mathrm{CLA}_{\mathrm{m}}=$ Interval from calving to commencement of luteal activity, based on monthly sampling. PLA $\mathrm{A}_{\mathrm{m}}=$ Percentage of samples with luteal activity the first 60 dayd postpartum, based on monthly sampling. CLA = Interval from calving to commencement of luteal activity, based on all samples. PLA $=$ Percentage of samples with luteal activity the first 60 days postpartum, based on all samples. 


\section{Discussion}

Our results showed that delayed ovarian cyclicity of cows can be predicted by progesterone measurements based on milk sampling schemes resembling the regular milk recording scheme (once a month). The similar outcome between the two different validation datasets, from two different countries, strongly supports this conclusion. The results for the two validation datasets were concordant although some differences existed between the two materials, e.g. the definition of delayed cyclicity differed by 10 days.

Inclusion of progesterone measurements in models gave a greater probability of predicting delayed cyclicity compared with the basic model, which included only the herd and animal risk factors, as shown by the significantly higher AUC values for the progesterone models (Table 2). Utilising the guidelines suggested by Swets (1988), as reported by Greiner et al. (2000), the basic model was less accurate, the progesterone models based on randomly monthly sampling (PLA $\mathrm{P}_{\mathrm{m}}$ and CLA $\mathrm{A}_{\mathrm{m}}$ ) were moderately accurate, and the models using all samples (PLA and CLA) were highly accurate. The sampling regime that was used here to calculate CLA and PLA, two to three samples per week, is impractical and expensive to apply in commercial herds. If an inline milk sampling system combined with progesterone analysis becomes available, it would allow more frequent sampling and use of biological models such as the one described by Friggens and Chagunda (2005).

The probability cut-off values selected in Table 3 summarise how well the different models worked. The very low cut-off point for PLA in the British validation data is probably a result of more frequent sampling in this data, which made it possible to detect very short luteal phases in the progesterone profile.

Setting up an optimal milk progesterone cut-off values require information about the incidence of delayed cyclicity in the population and consequences or costs for false-negatives and false-positives (Greiner et al., 2000). In the validation dataset the incidence of delayed cyclicity was $18 \%$ and others have reported incidences of 11-20\% (Opsomer et al., 1998; Royal et al., 2000; Garbarino et al., 2004), albeit with slightly different definitions of delayed cyclicity. The costs of false-negatives and false-positives were not calculated for the data in the present study. The Swedish data were obtained from one research herd and the costs may vary between herds. The proposed model may be used as it is, but probability cut-off values have to be set up considering sensitivity and specificity demands. With the selected probability cut-offs used in this study, $73-80 \%$ of all lactations with delayed cyclicity were correctly identified (sensitivity) with monthly milk sampling for progesterone analysis. Compared with the study of McLeod and Williams (1991), reporting 70\% incorrectly diagnosed follicular cysts and 58\% incorrectly diagnosed anoestrus with rectal palpation, the sensitivities in the present study were high using measurements based on progesterone analysis of monthly milk samples. The proportion of correctly identified lactations without delayed cyclicity (specificity) was below $70 \%$ for the basic model and above $80 \%$ for all other models. This is important because less lactations without delayed cyclicity were misclassified with inclusion of progesterone measurements in the model. This would thereby decrease the risk of unnecessary treatment of cows without delayed cyclicity.

The interval to first ovulation in cows with delayed cyclicity can effectively be reduced by hormonal treatments (e.g. Darwash et al., 2001), but the response to different treatments varied considerably between and within herds (Rhodes et al., 2003). Even if hormonal interventions are successful, cows with extended anovulatory intervals postpartum may be presented for veterinary diagnosis and 
treatment very late after calving. In Swedish field data, the interval from calving to veterinary examination of anoestrous dairy cows averaged 98 days, which lead to an average interval from calving to conception of 154 days for these cows $(\mathrm{H}$. Gustafsson, Swedish Dairy Association, personal communication). The proposed models with $\mathrm{CLA}_{\mathrm{m}}$ or $\mathrm{PLA}_{\mathrm{m}}$ gives the herdsman an opportunity to correctly identify four out of five cows with delayed cyclicity at around 60 days after calving. This would allow a decrease in the time range from calving to start of treatment compared with a diagnosis based on rectal palpation only (McLeod and Williams, 1991). Correct diagnosis and treatment of delayed cyclicity cows would increase the probability of getting the cows pregnant within a shorter time after calving. Information from progesterone analysis of milk samples from all cows postpartum could also become an important part of a preventive herd health programme in large, high producing dairy herds (Sheldon et al., 2006). However, the information obtained using these progesterone measures should be combined with other information (e.g. heat signs) to decrease the risk of treating false positive cows.

Ruiz et al. (1992) found in a cost-benefit evaluation of on-farm progesterone test that it was profitable for monitoring return to cyclicity but not for detecting type of clinical condition. Our approach here was to use milk samples for progesterone analysis that could also be used to improve the genetic evaluation for fertility in dairy cows, as previously shown (Petersson et al., 2007). The cost for progesterone analysis of milk samples could therefore benefit from management returns as well as from improvements in genetic gains for fertility. The inclusion of progesterone analysis in the analysis of milk samples in regular milk recording systems should therefore be considered. In Sweden, approximately $85 \%$ of all dairy cows are included in this system, which already today contains information about the other effects included in the models used in this study. Further studies should be conducted to determine the exact cost-benefit of an introduction of the proposed progesterone analysis of milk samples in the regular milk recording.

\section{Conclusion}

We showed that progesterone analysis in monthly collected milk samples, resembling the regular milk recording system, could be used to predict cows with delayed cyclicity with accuracy of $0.85-0.88$ within 60 days after calving. Measurements based on sampling frequencies of two to three times per week gave even higher accuracy (0.94-0.99) of detecting cows with delayed cyclicity. However, this latter sampling frequency is probably more suited for an inline progesterone indicator.

\section{Acknowledgement}

We would like to thank the staff at the Swedish experimental farm for their help with providing data for the study and to acknowledge the contributions of Prof. Anthony Flint, University of Nottingham, UK and Prof. John Woolliams, Roslin Institute, UK during collection of the UK milk progesterone data. This study was supported by the Swedish Farmers Research Council. 


\section{References}

Darwash, A.O., Lamming, G.E., Royal, M.D., 2001. A protocol for initiating oestrus and ovulation early post partum in dairy cows. Anim. Sci. 72, 539-546.

Esslemont, R.J., Kossaibati, M.A., Allcock, J., 2001. Economics of fertility in dairy cows. In: Fertility in the high producing dairy cow. British Society of Animal Science, Edinburgh, UK. Occ. Pub. 26, 19-29.

Fricke, P.M., 2002. Scanning the future - ultrasonography as a reproductive management tool for dairy cattle. J. Dairy Sci. 85, 1918-1926.

Friggens, N.C., Chagunda, M.G.G., 2005. Prediction of the reproductive status of cattle on the basis of milk progesterone measures: model description. Theriogenology 64, 155-190.

Garbarino, E.J., Hernandez, J.A., Shearer, J.K., Risco, C.A., Thatcher W.W., 2004. Effect of lameness on ovarian activity in postpartum Holstein cows. J. Dairy Sci. 87, 4123-4131.

Greiner, M., Pfeiffer, D., Smith, R.D., 2000. Principles and practical application of the receiver-operating characteristic analysis for diagnostic tests. Prev. Vet. Med. 45, 23-41.

Janson, L., Ahlin, K.-Å., 1992. Postpartum reproductive performance in cattle selected for high and low fat content. In: Proc. $43^{\text {rd }}$ Annual Meeting, European Association for Animal Production (EAAP), Madrid, Spain, pp. 93.

McLeod, B.J., Williams, M.E., 1991. Incidence of ovarian dysfunction in post partum dairy cows and the effectiveness of its clinical diagnosis and treatment. Vet. Rec. 128, 121-124.

Opsomer, G., Coryn, M., Deluyker, H., de Kruif, A., 1998. An analysis of ovarian dysfunction in high yielding dairy cows after calving based on progesterone profiles. Reprod. Domest. Anim. 33, 193-204.

Petersson, K.-J., Gustafsson, H., Strandberg, E., Berglund B., 2006a. Atypical progesterone profiles and fertility in Swedish dairy cows. J. Dairy Sci. 89, 2529-2538.

Petersson, K.-J., Strandberg, E., Gustafsson, H., Berglund, B., 2006b. Environmental effects on progesterone profile measures of dairy cow fertility. Anim. Repr. Sci. 91, 201-214.

Petersson, K.-J., Berglund, B., Strandberg, E., Gustafsson, H., Flint, A.P.F., Woolliams, J.A., Royal, M.D., 2007. Genetic analysis of postpartum measures of luteal activity in dairy cows. J. Dairy Sci. 90, 427-434.

Ratnayake, D.R.T.G., Berglund, B., Bertilsson, J., Forsberg, M., Gustafsson, H., 1998. Fertility in dairy cows managed for calving intervals of 12,15 or 18 months. Acta Vet. Scand. 39, 215-228.

Rhodes, F.M., McDougall, S., Burke, C.R., Verkerk, G.A., Macmillan, K.L., 2003. Invited review: Treatment of cows with an extended postpartum anestrous interval. J. Dairy Sci. $86,1876-1894$.

Royal, M.D., Darwash, A.O., Flint, A.P.F., Webb, R., Woolliams, J.A., Lamming, G.E., 2000. Declining fertility in dairy cattle: changes in traditional and endocrine parameters of fertility. Anim. Sci. 70, 487-501.

Royal, M.D., Flint, A.P.F., Woolliams, J.A., 2002a. Genetic and phenotypic relationships among endocrine and traditional fertility traits and production traits in Holstein-Friesian dairy cows. J. Dairy Sci. 85, 958-967.

Royal, M.D., Pryce, J.E., Woolliams, J.A., Flint. A.P.F., 2002b. The genetic relationship between commencement of luteal activity and calving interval, body condition score, production, and linear type traits in Holstein-Friesian dairy cattle. J. Dairy Sci. 85, 30713080 .

Ruiz, F.J., Oltenacu, P.A., Smith, R.D., 1992. Cost-benefit evaluation of on-farm milk progesterone testing to monitor return to cyclicity and to classify ovarian cysts. J. Dairy Sci. 75, 1036-1043. 
SAS Institute Inc., 2002. SAS User's Guide 9.1. SAS Institute Inc., Cary, NC, USA.

SAS Institute Inc., 2006. http://ftp.sas.com/techsup/download/stat/roc.html

Sheldon, I.M., Wathes, D.C., Dobson, H., 2006. The management of bovine reproduction in elite herds. Vet. J. 171, 70-78.

Strandberg, E., Oltenacu, P.A., 1989. Economic consequences of different calving intervals. Acta Agric. Scand. 39, 407-420.

Swedish Dairy Association, 2006. Husdjursstatistik (Cattle Statistics) 2006. Svensk Mjölk, S-101 24 Stockholm, Sweden.

Swets, J.A., 1988. Measuring the accuracy of diagnostic systems. Science 240, 1285-1293.

Wiltbank, M.C., Gümen, A., Sartori, R., 2002. Physiological classification of anovulatory conditions in cattle. Theriogenology 57, 21-52. 